\title{
6 Dispositional Analyses
}

Now that I have discussed language acquisition at length it is time to return to the core topic of this book: meaning. In this chapter, I indicate the rough outline of what I think an empirically validated theory of meaning in philosophy might look like. The starting point will be a brief return to primary meanings (in 6.1) and the role they play within the framework that I develop here. The major part of this chapter, then, is section 6.2. There, I will be piggybacking on Paul Horwich's idea to spell out the (relatively empty) claim that meaning is use by means of dispositional analyses. I think that this is exactly the right strategy to be dealing with use properties, i.e. the right strategy to counter the problem that constitutive use properties must eventually be identified with something else. Otherwise, there would be no 'access', as it were, to those use properties. In other words, if I only say that meaning is use without providing a corresponding method of stating the relevant use properties, I would be making a possibly true, but uninteresting claim. Associating use properties with something else (here: acceptance properties) provides an opportunity to evaluate the thesis in the first place.

Given a usage-based approach to meaning, dispositional analysis is without any alternative. However, I think that identifying use properties with acceptance properties is a mistake, as it easily leads to the impression that only truth-evaluable content can have meaning. One can't plausibly accept, for instance, sentences like "Hi there!" So, if one goes for a usage-based account that is supposed to be universally applicable to all areas of natural languages, one should indeed pursue dispositional analyses, but without the unnecessary constraint that all meaningful units have to be analysed with recourse to acceptance. This is what I will be proposing in the second half of this chapter. 


\subsection{The Role of the Refined Notion of Primary Meaning}

The paradox that I discussed in the previous chapter was this: there are good arguments against classically defined primary meanings; yet, a semantic theory that simply does away with primary meaning (and, thereby, the literality/non-literality distinction) seems highly implausible. As I have shown, one needs 'something like' ordinary primary meanings in order to account for such systematic effects as irony. Accordingly, I proposed-in 5.1.2-a refined definition of "primary meaning" that is acceptable from the point of view of $\mathrm{CxG}$ and usage-based approaches more generally, but which at the same time can be utilised in explaining literal/non-literal effects. There is some similarity between my 'primary meanings' and Horwich's 'core use properties', which are those 'explanatory basic properties' (Horwich 1998, 60) that account for the overall use of a term. The basic idea in both cases is that there must be some sufficiently general description of the meaning of a given term that can capture how this term gets employed, all things considered. This section is about how primary meanings figure in my own theoretic framework.

\subsubsection{Again, The Case of Malapropisms}

The core of the classical Davidsonian strategy of explaining the inferential mechanisms involved in processing malapropisms can be kept in my theory framework. Instead of truth-conditional knowledge (concerning referential relations), the current proposal is based on expectations. But the overall strategy is still pretty similar to Davidson's, i.e. starting from (the equivalent to) primary meaning, it ends with the very same 'pragmatic meaning'. For example, my proposal allows that one's ability to interpret a particular instance of "conifer" in terms of 'coryphaeus' is at least partly rooted in semantic knowledge regarding "conifer", that is, knowledge regarding 'literal' meaning. An obvious worry in light of these similarities concerns my original motivation for giving up truth-referential meaning in the first place. In the new framework, the inferential process requires, or so it seems, that its basis is primary meaning again: only expectations concerning primary meaning can go wrong. I shall first explain briefly why 
this worry is unjustified. Following this, I shall point out why the proposed framework fares better with respect to meaningless expressions.

The problem, discussed in 5.1.3, was this: in order for the inferential process to get off the ground, it is necessary that there are expectations about the use of the 'wrong' word, for example, "Konifere". However, one argument against TCS is that there are words whose meaning is such that it can't be explained by reference or by reference analogues such as satisfaction. Most obviously, this holds for classes of words that can only be semantically characterised by acknowledging their specific conversational function: e.g. "hello". Then there are also words that lack meaning entirely, which, however, are still 'comprehensible'. For instance, there are cases in which malapropisms involve meaningless words, as Davidson himself notes with respect to Lewis Caroll's Jabberwocky. For conceptual reasons, people can't have any expectations about how these words might be used. By assumption, meaningless expressions are such that people did not use them before. To be sure, it may be that people are able to identify similarities between meaningless expressions and meaningful counterparts. For instance, they might identify certain phonetic similarities; cf. "galumphing" (a term coined by Caroll) vs "gallop" and "triumphant". ${ }^{1}$ But if they do, they derive expectations concerning those meaningless expressions from their prior expectations concerning the meaningful counterparts. In any case, given that meaninglessness here can reasonably be equated with absence of prior use, there is nothing from which expectations possibly could have emerged.

The solution to this is simply this: the alternative proposal allows us to keep Davidson's machinery to a large extent; but this does not imply that understanding of malapropisms must always be inferential. The only thing I wanted to demonstrate above was that if sometimes understanding malapropisms involves inferences concerning, among other things, phonetic similarities between words, then this fact can be accounted for within the proposed framework. But often understanding is non-inferential or, at least, does not involve inferences concerning false expectations. Indeed,

1 Cf. the Wikipedia entry on Jabberwocky, http://en.wikipedia.org/wiki/ Jabberwocky \\#Possible \_interpretations \_of $\backslash$ words, accessed on: $25 / 03 / 2014$. 
"Er ist eine Konifere auf seinem Gebiet" is quite a good example in this regard, since many people have no idea what a 'Konifere'/'conifer' is. And by this I do not mean that they are not familiar with the scientific definition. Many people do not know that a conifer is, for example, some kind of tree. To put it another way, they form no expectations whatsoever about how "conifer" might be used. Hence, if someone uses the term, their expectations can't be false. Still, many people understand (utterances of) the relevant sentence perfectly well. ${ }^{2}$ This means that the intended interpretation ('expert') must be directly available to otherwise competent language users. In fact, this is what I want to argue for. People are able to immediately understand utterances, without necessarily considering 'literal' interpretations first.

That something roughly along these lines must be correct is evident from the facts. If people who, by assumption, do not understand "Konifere" individually are able to understand "Er ist eine Konifere auf seinem Gebiet" (call this sentence " $\alpha$ "), then inferences operating on the primary meaning (of "Konifere") can't be in play here. I claim that hearers immediately understand whole utterances, even if they are unfamiliar with certain 'parts' of it, because they engage in common cooperative activities with their interlocutors, and communication is one of the means they employ in executing these activities. In a typical situation, a speaker who utters $\alpha$ tries to convey the information that a particular person ('he') is an expert. The hearer, of course, uses all available information to figure out what $\alpha$ means. Most importantly, in a typical situation he would know (i) that the speaker intends to ascribe a 'positive' attribute to the person referred to by the pronoun "he"; (ii) that the construction "Er ist eine auf seinem Gebiet" means that he is a(n) __ in his area; and (iii) that, from the context of the preceding conversation, 'he' must be an expert in his area.

The third condition says, in effect, that a hearer already expects something like the intended interpretation. Bearing the following considera-

2 To be sure, this is an empirical claim that can't be justified entirely in the current context. However, I take it that, irrespective of the particular example, this phenomenon is common enough so that the reader is able to come up with examples that work analogously.

3 For instance, the speaker might employ an intonational pattern that suggests that a "Konifere" must be something positive. Also, the rest of the overall conversational context might exclusively support this conclusion. And so on. 
tions in mind, this does not seem too implausible. Keep in mind that utterances are always embedded in contexts. If the context is 'poor', i.e. if, for example, a speaker starts a conversation by saying "He is a conifer in his area" (to someone who does not understand "conifer"), the context offers little evidence as to what this could mean. That is true but not in conflict with my proposal, for it is equally true in such a case that, for the hearer, the intended interpretation is hard to grasp (if not impossible). If, on the other hand, the context is 'rich', it would entail more information that the hearer could exploit in figuring out the intended reading. For instance, $\alpha$ might be embedded in a larger conversational context:

Adam, you know, is a philosopher. He knows a whole lot about the meaning of life, about just societies, and about the ethical implications of animal experiments. He has written two books and forty-seven articles. Man, he's great. He is a conifer in his area. For real.

In this situation, one may reasonably assume that (i)-(iii) (or some reasonably similar conditions) are fulfilled and that the hearer is able to figure out the meaning ('expert') on this basis alone. In general, the overall context cuts down-for speakers and hearers alike-the range of possible interpretations of utterances. One might argue that the highlighted information in (iii) is chosen arbitrarily (by me as an informed theoretician), and that there are many more bits of information available in the abovementioned conversation that could equally qualify as relevant for a given utterance interpretation. For example, the information that Adam likes to write articles, etc. Many different kinds of information could have played the role of pointing the hearer to the most liekly interpretations. That is basically right. This, however, is not a problem for the hearer but for us as theoreticians. The problem is that it is hard to state a general rule that picks out the most relevant information that guides the interpretations of any specific utterance.

The general, schematic 'rule' for the hearer is simply this: pick out the interpretation that seems most probable. And given the 'data' in our little thought experiment, the hearer picks out 'expert' as the interpretation that seemed most probable. In a way, namely post hoc, the situation is similarly simple for the theoretician: given the way the hearer in fact interpreted 


\section{Dispositional Analyses}

the utterance (an ascription that is independently justifiable on the basis of non-verbal behaviour), the information that Adam is an expert must have been the most salient one. The only problem, so to speak, is that one can't state a rule in advance, independently from particular conversational contexts that would uniquely determine the meaning of an utterance. But that's just fine if one accepts that a semantic theory is unable to achieve this anyway. The only thing we can hope for is a theory that explains why utterances have the meaning they in fact have. And the answer to this question is: because speaker and hearer engage in common activities with common goals, and hearers exploit all available information, in particular contextual information, to determine utterance meaning.

In my example, the assumption is that the information that Adam is an expert, which triggers the hearer's inclination to interpret "conifer" as 'expert', was already implicit in the foregoing statement. Prima facie, this seems to render my explanation trivial, for, apparently, most of the time the decoded information is not implied by previous statements. In the case of malapropisms, the hearer must have some cues as to how to interpret a given utterance. My hunch is that if malapropisms are interpreted successfully (i.e. as intended by the speaker), then the relevant information was already implicit in the context. If it is not to be found in the utterances preceding the one in question, then probably somewhere else. Consider the following example:

One winter, I was looking out of my kitchen window. It was raining heavily. I turned to my friend, who was about to leave, pointed at the window and uttered (the German equivalent of) "Would you like to borrow a whisk broom?" Without hesitation, my friend pulled her umbrella from her backpack, waved it at me, and said "No, thank you, I've got one." Only after that we both realized what I had in fact said, and burst out laughing. (Glüer 2013, 347)

The information that was relevant for the hearer was, presumably, that she herself was about to leave and saw her friend looking through the window. Maybe Glüer also employed some more general information like that her friend is concerned about her; that the overall weather conditions were such that the hearer could easily assume that her friend could see that it 
was raining outside (even if the hearer was unable to see what her friend saw); and so on. Similar to the example before, the (non-linguistic) context was rich enough as to provide sufficient information for determining the content of the utterance.

The framework developed here suggests that if the (linguistic and nonlinguistic) context does not provide enough information, successful communication is hampered or impossible. Again, it is virtually impossible to state a general rule for this. In Glüer's example such a condition might be that the hearer did not see that she was looking out of the window, or if it was highly unlikely to rain that day, or what have you.

Probably the most vital source of information for expectations about how words might be used on future occasions is one's familiarity with their past instantiations. Accordingly, a very common reason for misunderstanding or unsuccessful communication is when the respective knowledge of word meanings diverge between speaker and hearer. In such casese.g. in conversations between a professional and a layman-the context is often too poor for the hearer to be able to interpret an utterance. The reason is that under normal conditions, a given speaker would assume (implicitly) that if the hearer shares some common semantic knowledge with the speaker, the utterance itself would provide enough contextual clues to figure out its meaning. Simply put, under normal conditions, speakers assume that their English-speaking interlocutors understand, say, "The Earth is round" as meaning that the Earth is round.

Speakers, therefore, very often accommodate their speech to ensure that the shared semantic basis between them and their interlocutors is as broad as possible. ${ }^{4}$ Also, speakers typically ensure that this shared basis is commonly known to be thus shared. A very familiar case is when you are abroad and you speak to some random person. In order to find out about whether there is some overlap between what you think your words mean and the semantic knowledge of the other person, you would typically ask questions like "Do you speak English?" Depending on the answer, you are justified in assuming that your utterances themselves (i.e. the linguistic

4 If they do not, their communication aim is probably not to convey the content of their utterances. For example, one might just want to sound competent and therefore use technical terms deliberately, assuming that their (exact) meaning is widely unknown to one's audience. 
context) will provide enough contextual clues to figure out their meaning, without needing to provide further, non-linguistic clues such as, e.g. gestures.

To see that the relevant context for successful communication is in fact very broad, consider this. A special kind of communication is written communication. Here, many factors that in serve purposes of disambiguation oral communication are unavailable (facial expression, shared visual field, gesture, intonation, etc.). Also, the typical speaker's sources for accommodating her speech according to the hearer's reactions are missing. For this reason many things that are possible in situations of oral communication are impossible, or severely complicated, in books and articles. Irony, for example, is often accompanied in speech by certain intonational patterns. These must be substituted by descriptions thereof in written work.

It is not always necessary to substitute non-linguistic clues, of course. But it is necessary if the context is otherwise too poor to trigger a particular intended reading. Metalevel descriptions, however, is not the only means employed by writers to get their message across. Consider the following: many statements in physics textbooks are presumably true (naïvely speaking). Equally, many statements in the Sherlock Holmes Novels are probably false (save for geographical facts concerning London). Anyway, textbook authors and novel writers are both equally 'successful' in getting their messages across, i.e. their respective audiences read their works roughly as intended. ${ }^{5}$ The example shows that even such abstract categories as text genre are part of the context and determine the conditions under which author and readership communicate with each other. Genre is one of many contextual factors that can determine a reader's expectations about how specific words or sentences might be used in what is reading.

I began with malapropisms, where the most interesting fact about this phenomenon is that readers/hearers understand sentence tokenings largely independently from the primary meaning of the falsely applied word (cf. "conifer"). My explanation for this ability was that interpretation always takes place in communication contexts in which producer and recipient

5 In construction grammar, there are even attempts to conceive of discourse units or whole literacy texts as constructions, i.e. there are attempts to broaden the technical notion "construction" accordingly such that it goes beyond the the borders of sentences: e.g. Günthner (2009, 2010), Imo (2010), and Östman \& Fried (2005). 
participate in some common activity or share some common goal, all of which helps the hearer/reader to figure out the intended reading. The range of linguistic and non-linguistic means that speakers use to enforce a particular meaning of their utterances and that hearers employ in determining what a speaker meant-this range is so broad that it is impossible to state a universal rule for how they do this. The only valid such 'rule' is the rather non-specific: it is all down to the context.

\subsubsection{Primary Meaning in the Current Framework}

Before I turn to a more general discussion of dispositional analyses, let me conclude this section with a few remarks on how the redefined notion of 'primary meaning' fits into the broader picture. The slogan of usage-based semantic theories is that meaning is use. In this book, I defend a specific variant of this claim, namely that the constitutive basis of meaning is the totality of actual tokenings of a given (word, sentence, etc.) type. 'Meaning', in the ordinary sense of that term, is the most appropriate descriptions thereof-for example, an analysis of relevant dispositions. Defending this claim against some objections will help to show what I mean here more generally.

It is important to stress right from the start that a whole family of objections can be forestalled by making clear that typing meaningful entities might involve a lot more than taking into account their formal properties plus relevant aspects of disambiguation. For instance, individuating the meaning of "bank" might involve more than just saying that tokens of that word type consists of such-and-such sequence of letters and that in certain contexts it may mean 'institution' whereas in others it could mean 'riverside'. Typing words and other meaningful entities might require relativisations to all sorts of things, including periods of time or social groups. I ask the reader to bear this in mind when I talk about 'all tokenings' of a given (word) type: this is always meant to be relativised to the appropriate (i.e. meaning-affecting) circumstances such as the relevant social group, the relevant period of time, the relevant conversational context, etc. (for this, see especially 6.2.1).

${ }^{6}$ Cf. also part three of this book. 
Generally speaking, foundational theories of meaning (reductionist theories) are concerned with explicating the underlying non-semantic properties that constitute semantic properties. A theory that explains meaning (a semantic property) in terms of use (a non-semantic property) is such a theory. Understanding is typically identified with a certain ability. For example, understanding a particular word is identified with being able to apply and interpret instances of this word, i.e. to know what it means. Now, if the meaning of a word were constituted by the totality of its past instantiations, a variety of problems would arise. Firstly, there is the problem that one typically wants to assume that all members of a specific language community (e.g. the English community) are competent in that they understand what words of their particular language mean. Presumably, qua being competent speakers, they must at least implicitly know the constitutive basis of word meaning. Secondly, the claim that meaning is total use seems to imply that the constitutive basis of word meaning is de facto not specifiable. There are infinitely many ways to individuate contexts, hence there are infinitely many ways to describe the contexts in which a word is uttered. Even if there were only one plausible context per utterance, the number of actual instantiations of a given word type would be far too high to actually 'list' these instantiations. Thirdly, knowledge of all actual word type tokenings, taken by itself, seems to be valueless anyway, i.e. such knowledge as such does not foster one's understanding. Grasping the meaning of a term is essentially an ability that involves abstracting from specific instances and coming to know valid generalisations.

I think all three worries boil down to the objection that, as it stands, "total use" is massively underspecified. I emphasise the totality of actual uses due to technical reasons, some of which I will discuss in detail in the following section. From a theoretical point of view, we are of course interested in generalisations, not in mere lists of instantiations. Therefore, I think it makes sense to make clear that-within semantics-we are typically dealing with, at least, two more or less different issues. There is a divide between the constitutive basis of meaning and semantic description. Typically, when people talk about 'meaning' in the folk sense of the term, they are interested not in its constitutive basis but in adequate descriptions. Constitutive bases constrain the range of adequate semantic descriptions. This, however, does not imply that changes concerning a given basis must 
involve corresponding changes with respect to the adequacy of semantic descriptions. Importantly, claims such as "meaning is total use" concern the properties that constitute meaning; they are thus not directly concerned with what is usually called 'meaning'. In this view, claims such as "meaning is total use" are abbreviated ways of expressing the thesis that 'total use determines meaning'. 'Meaning' itself is simply the most effective way of describing this constitutive basis (e.g. total use). This amounts to saying that 'meaning', as ordinarily conceived, is, strictly speaking, not total use but the most appropriate description thereof.

Concerning the three objections just mentioned, it is important to note that they oscillate between the two 'readings' of meaning. The first two objections say that equating meaning with total use prevents competent speakers from understanding and theoreticians from stating meaning. However, what is in fact unknown is only the constitutive basis of the meaning of each word. Neither ordinary speakers nor theoreticians know them. A philosophical theory might still make perfectly justifiable claims about the metaphysics of semantics. Simply put, I do not need to know individual tokenings of a word in order to justify the claim that individual tokenings alter the constitutive basis of semantics. For example, one reason is that each new tokening that a hearer/speaker is confronted with provides potentially new evidence as to what specific words might be useful in the future in order to reach specific aims (or recognise such aims in others). "Dog", for example, is used to refer dogs. This fact-assuming it is a factis constituted by each new "dog" tokening. As a hearer/speaker, one can infer this meaning on the basis of impoverished knowledge, without being acquainted with the whole constitutive basis.

Thus, distinguishing between semantic metaphysics and semantics in a more narrow sense helps us to see that understanding and semantic description are enterprises that are to a large extent independent of metaphysics. Similarly, the third worry-'listing uses without formulating generalisations seems valueless' - can be accounted for in terms of this metaphysics/description divide. The semantic descriptions we are dealing with are generalisations in the required sense (e.g. "hello" is used to greet someone). It is this type of knowledge that we would typically ascribe to competent users (as opposed to familiarity with total use). Plus, it is this type of knowledge that explains understanding in competent speakers or hearers; 
e.g. someone who knows that "hello" is used to greet someone arguably understands this term. The adequacy of such generalisations depends on the constitutive basis of all uses. If "hello" were to be used for different purposes in the future, then the mentioned generalisation would become invalid. The ordinary hearer/speaker does not need to consider the complete metaphysical basis of meaning in order to understand. His only 'responsibility', so to speak, is to form generalisations only on the basis of the segment of this basis with which he is familiar, i.e. the tokenings that he uttered or heard in particular conversational contexts.

\subsection{Meanings Are Dispositional Analyses}

I reject the identification of use properties with acceptance properties. The alternative I propose is twofold. Firstly, I think that it is best not to place any constraint whatsoever on the form of dispositional analyses other than that it must be efficient. Evaluating the value of a dispositional analysis (of the use properties that constitute word meaning) is like evaluating a lexicon entry: it is good if it conveys a sufficiently precise idea of the use associated with the term in question. In this sense, I think that there is ample reason to acknowledge that Horwich's sketches of analyses of terms like "red" are good approximations, i.e. analyses in terms of acceptance are perfectly legitimate in some areas. Secondly, I think that the 'search' for good dispositional analyses should start at the end of communication processes. Arguably, the dispositions people usually arrive at depend crucially on their interpretation of communication situations, i.e. the way they ascribe intentions and the success of using particular linguistic expressions relative to a given set of thus ascribed intentions. In 6.2.1, I say why I think meanings are dispositional analyses. In 6.2.2, I explain the explanatory role of intentions in semantics.

Relative to what I said at the end of the previous section, the title of the present section is not to be taken all too seriously. Meanings are efficient ways of describing their underlying constitutive basis. In my view, the latter is use. And my proposal is that the most effective method in this regard is dispositional analysis. In this sense, the claim that 'meaning is dispositional analysis' is not meant as revealing some irrefutable truth 
about semantics. Rather, the idea is that, considering all that is known about attempts to describe use, the dispositional method-à la Horwich but without the restriction to acceptance-is probably the most efficient method currently available.

\subsubsection{From Descriptions to Dispositions}

Returning to the recursion issue serves as an excellent starting point for the following discussion, which will lead to a more precise understanding of what meanings are. The extensive literature centering around compositionality and recursion is all inspired by the assumption that declarative sentences are the relevant unit for studying semantics. The mainstream literature suggests that sentence types are the most important theoretical entities when it comes to language comprehension. The paradigm examples in philosophy of language are the simplest examples, consisting of just subject and predicate: "snow is white", "Socrates is wise", and so on. ${ }^{7}$ I have already shown that such an approach is highly problematic in regard to other types of sentences (e.g. exclamations).

The appropriate solution here seems to be the following, which is radical but efficient. It does not really help to argue about sentence comprehension in terms of usage-based approaches versus truth-functional approaches, or anything like that. For they basically face the same problem in that they try to explain language comprehension in terms of semantic knowledge of constituents. I think it is a misconception to take for granted that 'sentence' is the unit that can be understood at all. Sentences (i.e. type-level, abstract units) are theoretical artefacts. Roughly put, thinking of sentences as the genuine objects of language comprehension is pretty much committing a category mistake. Borg, in particular, is likely to object at this point:

I will see or hear a sentence as meaning what it in fact does mean regardless of other things I believe or, in general, what I hope a given speaker is going to say. If you, as an interlocutor,

7 As I note repeatedly throughout this book, the more general problem in the study of semantics is that many people take written language to be their primary object of study. In philosophy, claims concerning spoken language often seem heavily influenced by the prevailing dominance of written language. For the relation between written and spoken language in linguistics see Linell (2005). 
decide to come up with the most surprising, most irrelevant utterance you can think of, it will still be the case that any sufficiently competent language user, within earshot and paying attention, could immediately interpret what the sentence you produced meant, even if they can find no relevant reason for your having spoken as you do. [...] Though I do not expect there to be an alligator in the corridor of my philosophy department, still a cry of "There's an alligator in the corridor!" means that there is an alligator in the corridor and, though I may have my doubts about the veracity of this report, it can lead me, cautiously, to investigate the matter. Yet, if semantic understanding were susceptible to expectations or to my general view of the world and my current situation, it is hard to see how this could happen. $(2004 b, 89-90)$

As I see things, there are basically two possible counterarguments. One is short; the other is shorter. The shorter reply is the following. What is at stake here is apparently understanding. Ascriptions of understanding, though, are defined in terms of what people do in specific situations. In particular, understanding is defined relative to how people behave in response to particular utterances. The abstract unit 'sentence' only comes into play in order to account for what enables understanding in the first place (if at all). However, sentences are not the objects of understanding. ${ }^{8}$ In any case, explanations of language comprehension always begin at the

8 To be sure, Borg's conviction that semantics is the study of context-independent meaning is not new. In fact, she is in good company, as the following quote is supposed to show:

The justification which permits the grammarian to study sentences in abstraction from the settings in which they have occurred or might occur is simply that the fluent speaker is able to construct and recognize syntactically well-formed sentences without recourse to information about settings, and this ability is what a grammar undertakes to reconstruct. Every facet of the fluent speaker's linguistic ability which a grammar reconstructs can be exercised independently of information about settings [...]. (Katz \& Fodor 1963, 173)

A slightly modernised version of this idea reads:

[...] what is said is determined linguistically. When a speaker utters a given sentence in a given context, the only intention that is relevant to what he is saying is his semantic intention, i.e. his intention concerning the resolution 
level of utterances. Note also that it would not help either to point out that someone who only knew that someone said 'There is an alligator in the corridor' would merely know that someone said something that means that there in an alligator in the corridor. This is perfectly explicable in terms of utterance comprehension. If the subject in question only understood (or knew) what a specific utterance meant in respect of certain formal properties (e.g. that the utterance consisted of specific words), then this means that the context was so poor that the subject was only able to retrieve information from that particular utterance on the basis of this utterance being an instantiation of a specific sentence type. Nevertheless, it is still the utterance that is understood (or is known to have a specific meaning).

I think it also would not help to point out that here we are specifically concerned not with understanding as such, but with semantic understanding. Within the broader picture of Borg's theoretic framework, the comprehension of 'sentences' (i.e. instantiations thereof) is a matter of processes going on in one's 'semantic module' (cf. Borg 2004b, especially chapter 2). In this view, 'semantic understanding' is independent from 'interpretation of communicative acts' (Borg 2004b, 90). Thus, what 'semantic understanding' is is not explicable in terms of behavioural dispositions (though the above quote might be read suggesting this), but only explicable in terms of (mere) knowledge of truth conditions. That is to say, it would seem that my objection might be a bit unfair, as I presuppose that utterances are the only proper objects of understanding. I can only partially agree. Indeed, I presuppose-and argue for the claim-that only utterances can be understood and I have problems with seeing what it means to 'semantically' understand context-free tokenings of sentences. But I do not think that this unfair or, in any way, could possibly undermine the claim that Borg did not

of any ambiguities and the fixing of any indexical references. (Bach 2001, 28)

Cf. also Bach (1994). The most recent expression of the idea that semantics can be pursued completely context-independent is this:

[...] to know the meaning of a sentence $\delta$ is for there to be a type of speechact $A$ and a form of content $\psi$ such that one knows that in a literal and unembedded utterance of $\delta$ the speaker is performing an act of kind $A$ whose content is of form $\psi$. (Schiffer 2015, 78) 
show that she is able to understand 'context-free' sentence tokenings. My general, methodological concern would be that if 'understanding' is completely detached from behavioural dispositions, as Borg suggests, ${ }^{9}$ then it is hard to see what would potentially count as evidence for attributions of understanding. On the other hand, if behavioural dispositions did play a role in determining whether a given subject understood some tokening of a specific sentence type, then it is unclear why that understanding should concern merely the sentence type but not that specific utterance. This is because the behavioural dispositions associated with the interpretation of a given sentence type systematically depend on how utterances of that kind are typically interpreted.

More generally, Borg seems to build her framework upon a certain idealisation. The idealisation lies in the implicit assumption that competent speakers all understand the same thing when they overhear a particular utterance. And that is probably false, because what they understand depends on a variety of different factors, including (i) which meaning they associate with the particular words uttered; (ii) what they consider relevant in a given context; (iii) on their overall cognitive abilities; and so on. In general, what people understand generally depends on the actual utterance, not on sentence types. There are several possibilities for Borg to object to this line of reasoning (all of which I only extrapolate from her writings). Firstly, she might object that I am confused about the explanatory end of linguistics. Linguists, or more generally: empirical theorists, typically try to capture generalisations. If I now explain understanding solely at the level of tokens, I neglect the fact that competent language users have one quite general ability, namely to recognise that someone who utters something of type $x$ means something that is commonly expressed by tokenings of

\footnotetext{
9 Borg $(2004 b, 81)$ :
}

If, for example, we treat grasp of literal linguistic meaning as the canonical derivation of truth-conditions for sentences [...], then semantic understanding can form part of a genuine language module, for this is clearly a function which is encapsulated and computational. Knowledge of meaning, on this kind of account, consists of knowledge of a proprietary body of information (the lexicon of the language) and knowledge of a set of rules operating only on that information $[. .$.$] .$ 
this kind (in case we were back at the level of types). One worry might be that an utterance-based (usage-based) conception of understanding might not be able to formulate generalisations (as it is individual utterances that get understood in this framework). To be sure, sentences are essential in order to formulate generalisations. But there is no contradiction here. If we want to express the idea that people who overhear "There is an alligator in the corridor" always understand that there is an alligator in the corridor, then we could just do this. Such an assumption (that I doubt is true) means that competent speakers of English understand utterances of this type similarly. This is a claim that would need to be justified by evidence showing that the behavioural patterns that people show as an immediate response to those utterances are sufficiently alike.

Secondly, Borg might raise the worry that although there are behavioural differences between language users when it comes to how they interpret utterances, it might still be the case that they interpret sentences alike. For example, people might actually respond differently to utterances of "There is an alligator in the corridor"; but what is common between competent speakers is that they, qua being competent, know that "There is an alligator in the corridor" means that there is an alligator in the corridor (which is knowledge that only partially determines their reaction). Competent speakers have different idiolects; what they 'know' about the meaning of a given sentence depends on what they 'know' about the words constituting that sentence. If competent speakers can have different idiolects, then there are two alternatives. One is to say that the phrase following the "means that" locution is interpreted relative to individual idiolects, in which case ascriptions of the form " $S$ knows that instantiations of sentence type ' $p$ ' mean that $p$ " is true. ${ }^{10}$ But this can't be true in Borg's view as this is specifically anti-Davidsonian. ${ }^{11}$ A second option is to say that the phrase following "means that" has a stable meaning, e.g. the one ascribed according to the theoretician's standards. However, in this case the ascription " $S$

${ }^{10} \mathrm{I}$ know that utterances of the form "There is an alligator in the corridor" (relative to my idiolect) mean that there is an alligator in the corridor (relative to my idiolect).

${ }^{11}$ Where by "Davidsonian" I mean that particular theory variant that takes Tarski's theory of truth as input and delivers a theory of meaning as output. As one of the readers of this book rightly pointed out to me, the 'later' Davidson (especially Davidson 1986) seems to defend the idea that, indeed, there are only idiolects, i.e. 'passing theories'. 
knows that ' $p$ ' means that $p$ " might turn out false, since its truth depends on what people associate with a given sentence. For the sake of simplicity, assume that what people associate with a sentence can be expressed in terms of truth conditions. Then the truth conditions that people associate with "There is an alligator in the corridor" might be different, depending on what, e.g., "alligator" means in their idiolect (e.g. to which set of objects it refers). If the associated truth conditions can differ, a generic ascription such as the one proposed by Borg can't be right.

A rather radical response would be to emphasise that the proviso "sufficiently competent" ensures that the relevant semantic knowledge that language users associate with a given sentence must be sufficiently alike. For one thing, this is pretty circular, since presumably competency, again, can be defined in terms of similarity of knowledge (e.g. the knowledge that "alligator" refers to alligators). Also, if a reasonable number of speakers are to count as competent, the standards for ascribing competency must be relatively low. As already remarked repeatedly throughout this book, the differences between individual 'competent' speakers are usually obscured by philosophers' tendency to discuss all too simple examples ("There is an alligator", "Snow is white", "It's raining", etc.). If you consider more complex examples (e.g. "Democracy is a goal worth pursuing"), you see quite easily that even competent speakers are likely to disagree about what particular sentences mean (independently of particular instantiations). And it does not help either to say that by definition competent language users must know what particular sentences mean, i.e. along the lines of: whatever "There is an alligator in the corridor" means, competent speakers must at least know that it means that there is an alligator in the corridor. Because then you are either referring to idiolects again (which is specifically antiDavidsonian $)^{12}$, or you are referring to competent users' ability to know that any sentence means what it de facto means, which is an ability that is fairly independent from their specific linguistic competency.

"Meaning" is a theoretical concept that refers to a particular state if it is used in expressions such as "Subject $S$ grasps the meaning of ' $p$ ' ". It refers

${ }^{12}$ Borg repeatedly remarks that her view is supposed to be a neo-Davidsonian one (e.g. $2004 b, 3-4$ and $2012 a, 3-4)$. Which is to say that, until recalled, she is committed to that Davidsonian perspective. 
to that very state subjects are in if and only if their behaviour correlates in a specific manner with " $p$ " utterances. ${ }^{13}$ What I propose, effectively, is to think of meaning as dispositional analyses. Dispositional analyses are approximations. When I say that "+" means addition, this does not mean that a given subject $S$ will answer my question "What is $1000+2$ ?" by saying "1002". However, such an answer is the one that is most likely (all things considered), given that the relevant subject is part of a language community in which "+" de facto means addition. Kripke, in Wittgenstein on Rules and Private Language (1982), discusses this at length in the context of private language. ${ }^{14}$ As a brief reminder: the problem is that if use (i.e. meaning) is couched in terms of dispositions, then one can't ever know with any absolute certainty the 'correct' set of dispositions (associated with a particular word). Because the set of dispositions is derived from the finite set of past manifestations (of particular word types). For now, let me just note that our actual success in conveying meaning ultimately determines that we are talking about the same dispositions. Kripke, when he says things like that he "uses the word "plus" to denote a well-known mathematical function' assumes that his readership understands him, thereby presupposing that he and the audience associate the correct dispositions with "addition"-for example, they would reply with "1002" rather than "1004" to the aforementioned question.

Dispositional analysis is no end in itself. Its success hinges on how well it 'summarises' the use of a given word, since the latter is what we are actually after. It is important to bear this in mind when weighing different possibilities of spelling out dispositions. For instance, dispositions must be attributed to objects. ${ }^{15}$ The obvious candidates for this are speakers and hearers. Assuming that communication is for the most part successful (people understand each other), I see no reason to think that there is a fun-

${ }^{13}$ Or, alternatively, for words: statements of the type "Subject $S$ grasps the meaning of ' $w$ "' refer to the particular state subjects are in iff their behaviour correlates specifically with utterances that contain the word " $w$ ". The reasoning behind this is simply this: although utterance meaning is theoretically primary, it is reasonable to suppose that many utterances that contain a word such as "apple" are structurally similar in some respects, namely in those respects that account for the meaning of "apple".

${ }^{14}$ See section 3.1.2.

${ }^{15}$ For a general overview of dispositions, I recommend Heil (2005). 
damental difference between speaker- or hearer-centered descriptions. ${ }^{16} \mathrm{I}$ therefore focus, as is common practice in philosophy, on the speaker in what follows. Accounting for the meaning of words in terms of the dispositions associated with its use has some neat advantages. I emphasise four of them and explicate them in turn. Dispositional analyses are (i) relativisable (to social groups, time, etc.); (ii) they are commonly accessible, which is an essential feature of meaning; (iii) they provide a framework for degrees of understanding; (iv) they can be designed in such a way that diachronic development gets incorporated very easily.

Ad (i): Dispositions can be easily relativised to different social (and other) groups and different historic times. This helps, for example, in describing the individuation of different meanings of homophones. It also allows for quite natural explanations for meaning shifts, which are difficult to handle in truth-functional frameworks and related theories. To be sure, dispositional analyses do not in themselves help to individuate meanings. However, they provide a quite straightforward means of modelling different meanings or meaning shifts, given that these are known. I think it is relatively fair to say that it is not the task of a decidedly philosophical theory of meaning to uncover semantic differences between homophones or shifted meanings.

${ }^{16}$ From the neo-Davidsonian point of view, the most problematic aspect of usage-based descriptions is its reference to intentions; speaker intentions in a speaker-centred scenario, mindreading in the corresponding hearer-centred framework. However, the dispositions to utter or interpret a specific utterance in a particular situation must be systematically alike. This is because natural language speakers are necessarily hearers, too. The dispositions of applying a word that I have as a speaker (relative to my intentions) are to a large extent determined by my dispositions of word interpretation as a hearer (relative to the intentions that I ascribe). Accordingly, if the overall success of human communication is given, then this success is probably due to the fact that speakers' dispositions are 'designed' in such a way as to match the hearers' disposition to interpret accordingly. Simply put, if I want to refer to salt, my disposition to utter "salt" in order to achieve this is determined by (i.e. matches with) those dispositions that, I suppose, I would have as a hearer if I were in exactly that situation my current interlocutor is actually in (what he is able to see from his point of view; what background knowledge he probably shares with me; what the prior conversational context was; and so forth). Therefore, it does not really matter whether the dispositions associated with a given linguistic sign are described in terms of speakers or in terms of hearers. 
I have shown that it is possible to give a usage-based account of "primary meaning" that does not presuppose that words actually 'have' their literal meaning in all actual conversational contexts. Rather, it seems more plausible to go just the other way around by saying that "primary meaning" must be spelled out in terms of uniform expectations, thereby picking out specific subclasses of utterances (namely those that correspond to literal uses in classical terminology). Also, I have noted that "primary meaning" may be defined in terms of the 'homogeneous majority of uses (if any)'. ${ }^{17}$ I should now spell out more precisely what this claim amounts to.

The qualification "homogeneous" in my definition is particularly important. Several utterances of a word qualify as having the same meaning by exemplifying similarities; eventually, these structural similarities justify counting several utterances as instances of one particular type. For example, it has often been noted that some words have such a shallow 'core meaning' that their actual-'literal'-meaning differs effectively with each new linguistic context. ${ }^{18}$ The classical example here is "cut", presented by Searle:

Consider the following sequence of rather ordinary English sentences, all containing the word "cut".

1. Bill cut the grass.

2. The barber cut Tom's hair.

3. Sally cut the cake.

[...] It seems to me the following is more or less intuitively obvious about this list. First of all the occurrence of the word "cut" $[\ldots]$ is literal. There is nothing metaphorical or figurative in our understanding of any of those sentences. (1980, 221)

17 The "if any" simply rules out those words that lack (what I call) primary meaning. There are some words that are perfectly meaningful, yet lack proper primary meaning, since no homogeneous set of its tokenings may be determined yet: for example, the German term "wulffen" during its first two or three months of application.

${ }^{18}$ In contrast to indexicals, what differs from context to context is not merely semantic value (e.g. the referent) but meaning as such, i.e. the property that determines semantic value. 
The most prominent, slightly more recent reconsideration of this topic is in Recanati's work. In discussing a variety of similar examples, he notes the following concerning "red":

What is it for a car, a bird, a house, a pen, or a pair of shoes to count as red? To answer such questions, we need to appeal to background assumptions and world knowledge. Linguistic competence does not suffice: pragmatic fine-tuning is called for. [...T]o determine a suitable sense for complex expressions, we need to go beyond the meaning of individual words and creatively enrich or otherwise adjust what we are given in virtue purely of linguistic meaning. We must go beyond linguistic meaning, without being linguistically instructed to do so, if we are to make sense of the utterance. $(2005,183-184)$

The basic idea is always the same and indeed quite simple: "cut" (and the like) seems to differ enormously in meaning, depending on what it takes as object, so to speak. It goes without saying that something like a 'core' meaning is common to all those variants. There are, though, different things that can be literally cut (grass, hair, etc.) and different ways of doing so. Hence, "cut" instantiations are to a large extent heterogeneous in certain respects. Still, one is typically inclined to say that "cut" has primary meaning. Thus, something must be in common between all literally interpreted "cut" utterances: the instantiations must be homogeneous in some sense. The trick is to acknowledge that, due to the different varieties of cutting, the homogeneity of "cut" utterances must be paraphrased in very general terms, ${ }^{19}$ whereas the superficial heterogeneity is attributed to regularities in the use of those words that denote the things cut ("grass", "hair", and so on). Ultimately, homogeneity of use is what determines that several

\footnotetext{
${ }^{19}$ Along the lines of: "to cut" is a verb that often expresses a reduction of a certain mass (of grass, hair, etc.), where the object that retains the remaining amount (of grass, hair, etc.) is also its syntactical object (grassland, head, etc.). Note, though, that the underlying problem that Recanati describes remains. A 'liberal' formulation of the relevant meaning is incapable of solving it. The problem persists that the abstract meaning of "cut" as such does not suffice to determine sentential truth conditions in particular contexts. In order to determine (literal) truth conditions, one needs to consider contextual features (e.g. cotext, intentions, common knowledge, etc.) that are not 'allowed' at the 'semantic' level in truth-conditional theories such as Borg's.
} 
tokenings of 'words' belong to the same word type. Because we would not want to individuate word types solely according to their spelling or other formal features. That would be absurd. Rather, we want word individuation processes to be guided by differences in use: for example, word type 1 of "bank" is used to refer to riverbanks; word type 2 is used to refer to institutions. Thus, if "to cut" actually is one word (type), this must be reflected in at least some, albeit very general homogeneity of all its supposed instances. ${ }^{20}$

The "majority" in "the homogeneous majority of uses" highlights the fact that the "primary" in "primary meaning" makes sense only in sharp contrast to some 'derived' or 'pragmatic' meaning. In my terminology, 'pragmatic meaning' is what all (meaningful) utterances have. In this view, 'primary meaning' is the meaning that words have if they are used (what is typically called) 'standardly'; e.g. "dog" in contexts in which it is used to refer to dogs. These two things might look circular at first sight. Firstly, the use of "reference", which might look as if I were smuggling referential relations back into my account. This, I think, would be a misunderstanding. Nowhere in the text do I say, for example, that the meaning of "dog" is (or can be given by saying) that it refers only to dogs. On the other hand, it is an empirical fact that very often people use "dog" in order to refer to dogs. If I now pick out this particular fact in order to characterise the likely primary meaning of dog, then this 'citing of facts' is fairly independent of one's underlying semantic theory, i.e. fairly independent of whether you think that meaning is, for example, reference. Secondly, the way I describe primary meaning might look dangerously circular. If using words with their primary meaning is using them standardly; then what is using them standardly? Supposedly, using them with their primary meaning. Again, I

${ }^{20}$ In section 8.3, I link my discussion of the distinction between the 'constitution base' of a word and its appropriate 'semantic description' with the question of what determines that a particular expression token belongs to a specific expression type. In other words, that section describes how, I think, tokens should be 'counted'. In this sense, that section also answers the question what it takes for any given set of expression tokens to be homogeneous: tokenings are homogeneous in the relevant sense iff there is a theoretically fruitful way of describing them as instantiations of a particular type. Of course, such a notion of 'homogeneity' presupposes that words already have been typed accordingly. But that seems justified, as it is not the task of a theory of meaning to provide its own (full-blown) account of how expressions are typed. 
think this would be a misunderstanding as well. I define "primary meaning" in terms of majorities of use. Strictly speaking, it is perfectly possible (i.e. in principle possible) to look naïvely, without prior theoretic understanding, at the whole set of actual word type instantiations. In sorting all instances according to certain similarities among them, one could find out that most instances share a specific feature. For example, one might find out that most "dog" instances share the feature that people use them in order to refer to dogs. Now, in characterising my own account, I presuppose that competent speakers of English are, in general, aware of such empirical facts. Presupposing such knowledge does not render the account circular.

Words 'have' their primary meaning in a subset of cases relative to all actual instantiations of the corresponding type. It is relatively easy to recognise a "dog" utterance as an instance belonging to a specific type, e.g. due to phonetics, spelling, etc. ${ }^{21}$ Similarly, it also quite straightforward to determine whether some such instances form a majority, given one's ability to recognise homogeneity. Accordingly, in my terminology associating a primary meaning with a given term means forming expectations about the future application of this word that is based on one's ability to recognise (implicitly) that there is a majority of past instantiations of this word type that shared relevant commonalities. For example, the commonality might be the circumstance that, in the majority of cases, "dog" utterances have been used to refer to dogs.

Before I return to the actual topic-dispositions and relativisations-let me very briefly add a caveat. The 'homogeneous majority' that people consider in order to form their expectations about 'standard usage' happens simultaneously with or after disambiguation. Here is a very illustrative example. "Bank" is a word whose instantiations are by and large distributed equally amongst its two major interpretations ('riverbank' and 'institution'). That is why, strictly speaking, no clear majority can be determined here. So if I say that the 'homogeneous majority' of cases determines expectations, I have in mind the majority of cases within the set of tokenings of one interpretation. This is because it is possible to have distinct nonliteral (i.e. minority) uses for both types separately. The same applies to cases in which there are two or more possible interpretations, but one of

${ }^{21}$ Müller (1996) offers some nice remarks on type recognition. 
them is so prominent that, in fact, it supplies the majority, all instances considered (e.g. "great" as 'excellent' vs 'large').

Back to dispositions, then. Dispositions have the significant advantage that they must be relativised in several respects, anyway. They thus provide a natural framework for distinguishing homophones, distinct meanings in particular social groups, different meanings according to contextual factors, and so on. Let me explain. Relativisation to social groups will serve as an example. In German, the word "Mongo" (eng. "mongo") differs slightly in meaning depending on the social group within which it is used. ${ }^{22}$ For sake of simplicity, I consider only its offensive usage. The ordinary, established variant is to use it, in appropriate circumstances, with racist connotations. In the idiolects of today's youth, "Mongo" means, roughly, 'idiot'-without any racist connotations whatsoever. Thus, we have one word type that is associated with slightly different sets of dispositions regarding today's youth and prior generations. These differences in meaning trivially fall off any empirically informed dispositional analysis of "Mongo", as one needs to relativise dispositions to all meaning-relevant factors. Simply put, one can't just say that a particular word type $w$ is associated with such-and-such dispositions simpliciter. Rather, dispositions require objects to which they can be attributed (like properties) and circumstances in which they take effect (in philosophical prose, 'antecedent conditions').

I can imagine that the most likely response to this argument is this: trivially, if "Mongo" falls into two different types in modern German (as secured by the description), then this is just as easy to account for in truthconditional semantics as it is in use theory. Either "Mongo" is actually two types with two different intensions (and thereby extensions (e.g. the set of idiots and something else), or it is just that two different connotations are

22 "Mongo" differs with respect to its use in adolescents and adults, though it is arguably only one word type (a fortiori by classical standards). The following is a quote from a recent newspaper article: 'A spokesman of the ministry of defence said in Berlin that, apparently, the colloquial [German] word "Mongo" can most likely be identified with 'Idiot'. It does not in a pejorative manner refer to Asian people', Frankfurter Allgemeine Zeitung, 27/02/2013, my translation. For the record, the original reads: 'Ein Sprecher des Verteidigungsministeriums sagte in Berlin, das Slangwort "Mongo" sei offenbar in der heutigen Jugendsprache am ehesten mit "Idiot" gleichzusetzen, es beziehe sich nicht in herabwertender Weise auf Menschen asiatischer Herkunft.' 
associated with it. In the first case, there are two words to which, respectively, two different references can be attached. In 'Tarskian' terminology, the two relevant types get associated with two different base clauses. In the second case, truth-conditional semantics could just treat it as a single word and leave connotations to pragmatics. ${ }^{23}$

The reply does not succeed for the following reasons. Treating "Mongo" as one word whose different connotations become relevant only at a pragmatic stage is highly implausible, since this would require that both variants can be treated equally because of a common truth-conditional impact (rooted in an alleged referential relation). That is absurd, for truth conditions are absolutely irrelevant in determining the meaning of "Mongo". Not only do both variants not share a common intension (and thereby extension), they both have no 'extensional' commonality. To see this, consider the most likely candidate for the offensive reading: the intension that picks out the set of idiots. It makes no sense to say that " $x$ ist ein Mongo" is true iff $x$ is an idiot, or anything reasonably similar. The reason is that this intension is not even accurate for offensive use of the term: people typically do not refer to anyone in these cases. Yet, the word is meaningful unless you define meaning in terms of extension. The meaning of "Mongo" can be explicated, e.g., in terms of its conversational function: it is successfully applied if the addressee feels discredited, etc. ${ }^{24}$

Given that "Mongo" has two distinguishable meanings in modern German, this might be captured in truth-conditional semantics by simply postulating two types. One might even assume-if only for the sake of argument-that this could be done be postulating two different intensions. ${ }^{25} \mathrm{I}$

${ }^{23}$ For example, by following Borg in claiming that pragmatics is only relevant for communication; which, again, is not to be dealt with by a theory of meaning, since the objects of study in semantics have their meaning independent of the communication-related ends they serve.

${ }^{24}$ I suggest that, in general, some classes of words are best described by recurring to the conversational functions that they fulfil. These classes are particularly hard to integrate into truth-conditional semantics, as they lack content that affects truth-evaluability. The most relevant examples in this regard include words that contribute absolutely no such content, but which at the same time have a very precise, easily specifiable meaning: e.g. "hello", "come on", "ouch", etc.

${ }^{25}$ The argument would run as follows: if you insist that there are two distinguishable uses in younger and elderly people, then this necessarily implies that these assumed differ- 
will not argue against this possibility. Note, however, that the only possible reason for postulating two word types is due to differences in use. In this regard, there is no difference at all between use theorists and rival theories. A proponent of truth-conditional semantics is thus forced to claim that there is a fundamental difference between finding out what a word means (the epistemology of semantics, if you like) and finding out what meanings essentially are (semantic metaphysics). But this way out is blocked, as there is nothing more to meaning over and above what is suggested by empirical evidence, i.e. use.

Both ways, type differences of words boil down to differences in the dispositions associated with them, i.e. the properties that constitute their overall employment. Relativising dispositions to social groups is probably the most effective way of attributing differences in use to these groups (e.g. youth vs elderly people). Further relativisations work absolutely similarly. For instance, one could relativise the dispositions of using "cool" to different situational contexts ${ }^{26}$ in order to distinguish two types: e.g. 'cold' and 'awesome'. Or, one might relativise dispositions to time or region: think of "tall person" in Asia vs in North America; or in 2014 vs in 311 BC. There are probably many such differentiations, contrary to what is suggested by the typical, in fact obligatory relativisation to language communities. Which relativisations are necessary to make is, of course, an empirical question. My point is that dispositions are a particularly adequate means to meet this need, as they have, so to say, an in-built demand for such relativisations.

Ad (ii): A recurring theme in the literature on the semantics of words and concepts is public access to meaning. Here, I briefly summarise the relevant parts of the discussion. Theories that emphasise the importance of the internal structure of speakers in the context of meaning determination (of words, of concepts) face the problem that for many different words the speaker's disposition to apply those is identical (cf. the narrow/wide

ences manifest themselves in attributing "being a mongo" to different sets of objects. Subject to correction for misapplications, these attributions hint at different intensions of the two involved types.

${ }^{26}$ Here, I mean contexts that differ in regard to whether this "cool" variant is applicable. Say, " $\mathrm{cool}_{1}$ " is applicable in linguistic contexts that suggest that temperature is at stake; " $\mathrm{cool}_{2}$ " otherwise. (This is simplified and for illustration purposes only.) 
content debate, for instance $)^{27}$; and that individual dispositions can't determine meaning anyway, for this would render successful communication implausible (cf. also the debates on inferentialism or holism) ${ }^{28}$. The worry is that the dispositions that presumably constitute speakers' overall language use are, with nomological necessity, not directly accessible to their interlocutors (i.e. they can only infer them). That is a serious problem, because two equally legitimate aims collide. I propose to go something like a middle way by claiming that both sides are right: meaning is determined by individual speaker dispositions and, at the same time, meaning is publicly accessible. Concerning the first point, meaning simply must be determined by speaker dispositions, because if meaning is use, then there is no way of finding out about meaning other than scrutinising speakers' dispositions to apply language. Accordingly, I would suggest that dispositional analyses are the most efficient way of capturing use. The second point is slightly more complicated, which is why it is worth going into a bit more detail.

For the following argument, I take the tentative results of preceding sections for granted. The meaning of a word is determined by the totality of actual past instantiations of this type. Barring some exceptions, this implies that nobody can have perfect knowledge of meaning, for nobody is familiar with all past instantiations of a given word type. Concerning dispositions, it is important to note that the individual dispositions to apply (or understand) a given term are determined by acquaintance with only a limited set of past instantiations. ${ }^{29}$ Yet, there is an 'ideal' set of dispositions, namely the set one would associate with a given word if one had heard or otherwise experienced all its past instantiations. ${ }^{30}$

\footnotetext{
${ }^{27}$ Fodor (1987), Loar (1988).

${ }^{28}$ For overview articles, consult Cohen (1999) and Pagin (2006). Devitt (1993) is a critical discussion of meaning holism.

${ }^{29}$ In linguistics, this is known as the 'bottleneck problem'. The 'bottleneck' refers to the circumstance that, roughly put, every speaker hears a different set of word instantiations during their lifetime; still, every speaker (of a given language) ends up with the 'same' semantic knowledge. For each generation, the semantics of a given language (e.g. the semantics of "snow") goes through this bottleneck, whereby, interestingly enough, it retains its relevant properties (cf., again, Kirby 2002).

${ }^{30} \mathrm{I}$ come back to this in 8.3.
} 
Regarding public access to meaning, there are two separable problems, I think. Firstly, the meaning of words is a property of whole language communities, while the relevant dispositions to apply words belong to individual speakers. I call this the 'community problem'. Secondly, every speaker has a slightly different set of dispositions to apply a given term, while different people are nevertheless able to talk about the same thing. I call this the 'communication problem'. Now, the trick is to utilise the notion of an 'ideal set of dispositions'. To begin with, note that this is only a terminological definition. Of course, the 'ideal' set is not ideal in the folk sense of the term. Rather, it is ideal in that it is that particular disposition one would arrive at if one's overall application of a term were based on the experience of the totality of all word instantiations of this type. My argument will be that the theoretical notion of an ideal disposition can explain away both problems at hand.

I begin with the communication problem. Successful communication requires, or so people sometimes claim, that two or more people are able to talk about the same thing, e.g., snow, Johnnie Walker, the Seventh Sun, etc. If meanings were dispositions, then nobody would ever be able to talk about the same things, since, in fact, no two speakers ever share the exactly identical set of dispositions (concerning language use). I think that the flaw in arguments of this type is that they presuppose identical dispositions for communication success. Before turning to the key issues, let me begin with a short remark on the terminology employed in this objection. Apparently, the vocabulary that is used here is tendentious. Speakers' ability to 'talk about the same thing' is sold as the relevant hallmark for communication success. This is clearly inspired by referentialism, i.e. the prevailing idea that a theory of meaning is first and foremost a theory of reference. Doing away with this terminology will help to make clear what is actually at stake.

Communication success is, roughly put, a relation between a speaker's intentions and the results of his communication efforts. No matter what philosophers believe that communication needs in order to be successful, a communicative act such as "Could you please pass the salt?" is successful if, and only if, the addressee passes the salt to the speaker (given that was his intention). ${ }^{31}$ In particular, the success can be determined independently

${ }^{31}$ See Pencil (1976) for a comprehensive review of the relevant literature. 
from whether "salt" successfully refers to salt. ${ }^{32}$ Thus, the "bridge principle' that is required to reconcile necessarily diverging dispositions with successful communication is this: people are able to talk 'about the same things' if the semantic properties of their respective idiolects are sufficiently similar. Consider Wittgenstein's prominent example. We all have different concepts of chairs-and, hence, associate slightly different meanings with "chair". Our respective dispositions to apply "chair" to any given object are (supposedly) never $100 \%$ identical. Remarkably enough, communication is still successful with respect to chairs. In other words, communication success is based on similarities of our dispositions to apply terms (or interpret others' utterances), not in their identity.

In technical terms, this point can be captured thus: the dispositions of two speakers, $S_{1}$ and $S_{2}$, concerning the applicability of a word $w$ are similar iff there is a significant overlap between the situations that specify $w$ 's applicability for $S_{1}$ and $S_{2}$, respectively. The more overlap between these sets of situations, the more similar $S_{1}$ 's and $S_{2}$ 's use of $w$. The basic idea here is this: success means success in specific situations. Significant overlaps of situations in which two speakers would apply given terms ensure that their expectations regarding the use of these terms are compatible. Again, compatible expectations lead to communication successes. Please note that the descriptions of the respective sets of situations can be quite specific (depending on one's analysis interests). "Chair", for example, is a word whose applicability is somewhat vague. Interestingly, communication about chairs is still often successful. I am usually not surprised about what people get me when I asked them to bring a chair. The obvious explanation for this is that the set of situations in which a word is applicable is determined, among other things, by the relevance of a potential tokening. Roughly put, in the research on vagueness we can distinguish three different cases (ignoring higher-order vagueness): 'applicable', 'not applicable', and 'unclear whether applicable'. Philosophically interesting questions like reference-fixing (and, thereby, truth conditions) are determined-one may reasonably suppose-by one's overall inclination to apply a term. However, in situations in which success is relevant, people's dispositions are probably guided by only the clear cases, where the clear cases are those

${ }^{32}$ Whereby I do not mean that reference relations are never involved in explaining success. 
of which they think that their interlocutor's dispositions are the same as their own. This explains why even in cases that involve instances of such words like "chair", communication success might in principle be exceptionless. It is because people are capable of recognising those situations relative to which their understanding of the applicability of a word is compatible with the understanding of others. Accordingly, they are able to 'confine' themselves to these overlapping situations whenever the applicability of a word is relevant for their communication success. In most cases, the range of possible overlap is so huge that one is easily led to the impression that communication is always successful, i.e. that we are always in a position to 'talk about the same things'.

Furthermore, our respective dispositions are, to a large extent, impressively similar-especially concerning connectives, termini technici, proper names, etc. This is because they converge to the ideal set of dispositions. The individual sets of dispositions (of speakers) diverge, because particular speakers are confronted with only a limited set of word type instantiations (plus differences regarding their belief sets and their remaining semantic knowledge). Note, however, that the individual instantiations themselves with which language learners get confronted are also very, very similar: for example, "snow" is very often used to talk about snow. Thus, it is highly plausible to assume that the similarity of actual "snow" utterances is passed on to the individual sets of dispositions that language learners derive from a particular subset of those utterances. It seems indeed plausible to assume that this effect is fairly independent of the fact that the particular set of instantiations with which individual speakers are confronted differs from the corresponding sets of their interlocutors. Thus, ideal dispositions solve both problems at once. Concerning the communication problem, it is important to acknowledge that communicational success can only be 'measured' in terms of fulfilment of intentions, for which similarity-as opposed to identity-seems to be sufficient. Concerning the community problem, I have shown that it is possible to attribute meanings to the words of whole language communities by abstracting from individual dispositions, which is unproblematic because the latter are remarkably similar, anyway.

One last note on similarity. I assume that communication success is rooted in similarities of individual sets of dispositions, which again is presupposed to be rooted in similarities of individual tokenings. Granted this, 
it is easy to see that the strong, widespread conviction in philosophy of language that the semantic knowledge between any two competent speakers of a language such as English is identical stems from a biased choice of example cases. The by far most obvious example that illustrates this is logical connectives. One of the most popular examples especially in the philosophically minded literature on theories of meaning is the connector "and". Superficially, choosing comparatively simple examples serves the purpose of explaining in simpler terms mechanisms that work similarly in more complicated cases. The meaning of "and" is supposedly simply its contribution to the truth value of a sentence as a function of the truth values of its conjuncts ( $\ulcorner p$ and $q\urcorner$ is true iff both $p$ and $q$ are true, false otherwise). The following argument does not just concern truth-functional connectives, which are somehow special in that they only 'relate' truth values. The important point is theoreticians' tendency to discuss word meanings that are easily specifiable due to their (relative) univocal use (e.g. the alleged fact that "snow" refers to snow). Up to a certain point, it seems that exemplifying complicated issues (e.g. meaning) by using relatively simple examples (e.g. "and" or "snow") is a perfectly legitimate strategy. However, it gets problematic as soon as the simplicity of the chosen examples obscures what is actually happening. The assumption that communication success is essentially rooted in the alleged identity of dispositions associated with individual words seems to be due to the fact that, as far as the chosen examples are concerned, the similarity of individual dispositions is indeed overwhelmingly obvious. When I say that example cases are chosen based on biases, I do not intend to imply that the complexity of the chosen examples does not go beyond the complexity of "and" or "snow". It is only that people-for good reasons, by the way-tend to choose examples that have clear, unambiguous semantics. Anyway, it would be odd if that were different. But a side effect of this strategy is that people often also tend to think that the relevant dispositions to apply a certain term are more or less distributed equally among competent speakers. And that certainly holds only for the examples typically chosen, if at all.

Ad (iii): Obviously, some people understand some words better than others. I have defined elsewhere (3.2), following Horwich (1998, 16-18), that to understand is to have implicit knowledge of the use of a given term. Even opponents must admit that knowledge of meaning comes in degrees, and 
that these degrees of understanding manifest themselves in how the term is used. The most natural way to explain these differences in use is by referring to the differences in the sets of implicit knowledge every language user associates with a given term. Even more importantly, not only is this strategy unavailable to the opponent of usage-based approaches, but there is no obvious alternative that may be offered.

Within a usage-based framework, it is-barring complete descriptionsrelatively easy to 'model' degrees of understanding. If meaning is total use and use is described in terms of dispositions, then full understanding may be equated with full, implicit knowledge of this use. ${ }^{33}$ Accordingly, degrees of understanding can be understood in terms of divergence from this set of knowledge. Apparently, to really model these divergences might be very difficult or indeed impossible. But this does not undermine the present framework, for the following two reasons. ${ }^{34}$ Firstly, it is an answer to the question what degrees of understanding are (i.e. an in-principle answer), whereas, as I said before, other theories do not provide such an answer. Secondly, the underlying problem is not that modelling degrees as such was especially difficult, but finding the right dispositions in the first place.

There is an important area in which privileged semantic knowledge is possible, namely self-knowledge. A person's knowledge regarding the semantics of his own idiolect is special in that introspection is available as a possible source of evidence. I said that understanding implies implicit knowledge of use. I have a particular, though not perfectly reliable, epistemic access to my dispositions that I do not share with anyone else. The least I can do is go through different imagined scenarios and ask myself whether I would be disposed to apply a given term in such a situation.

33 This directly follows from how "understanding" has been defined plus the dispositional analysis of what meaning is. By the way, note that, except for some rare cases (coinage, omniscience, termini technici, proper names), full knowledge of this kind is impossible, which is highly plausible.

${ }^{34}$ A similar problem with modelling appropriate distances arises in the area of truthlikeness (Oddie 2014). Issues concerning only the modelling leave unaffected the intuitive grasp of which propositions are 'closer' to the truth than others. For instance, if the actual amount of rain was $50 \mathrm{cl}$, a theory that predicted $50.3 \mathrm{cl}$ was closer to the truth than the one that predicted $17 \mathrm{cl}$. Analogously, the difficulties in modelling divergence from the ideal set of dispositions leave unaffected the intuitive grasp that some people's understanding of a given term seems 'better' (closer to the ideal) than others' understanding. 
This ability explains both why one has the impression that self-knowledge is possible (because my own dispositions are 'transparent', so to speak) and why self-knowledge is a relatively reliable source of evidence. It is because we continuously use language, hence we invariably check the applicability of words according to our own standards. ${ }^{35}$ It would, however, be a mistake to transfer this conviction that individual semantic knowledge is relatively reliable in respect to the idiolects of others or to the semantics of whole languages (i.e. the idiolects of a language community taken together). For here, one's implicit assumptions about others' use of a word is always an approximation whose scope is limited by severe epistemic restrictions. The restrictions result from the fact that every speaker of a language community is familiar with only a limited set of actual tokenings (cf. 'poverty of the stimulus' arguments), which indicates possible future use. By the same token, this line of reasoning shows why perfect semantic knowledge is possible in some cases. For example, it is possible to completely understand proper names. The reason is simply that a limited evidence basis will result in the same assumptions regarding future use as familiarity with all available evidence would result in. ${ }^{36}$

Ad (iv): Diachronic developments are very important in semantics, grammar theory, and general linguistics. Words, morphemes, and syntactic constructions might today have a different meaning than they had some time ago. There is broad consensus that semantics develops on different timescales. In artificial settings, meaning shifts occur quite frequently; very often they are even continuous (cf., for instance, the work of Simon Kirby). There are some classes of words that are hardly ever affected by meaning shifts, the most prominent examples of which probably include logical connectives, as indicated above. Presumably, everything else lies in between

\footnotetext{
${ }^{35}$ This is not to say that this proves that our assumptions concerning our own dispositions or others' dispositions need to be 'correct' in the Kripkensteinian sense. Still, we 'continuously check the applicability' of a term in the-relatively weak-sense that we have certain assumptions about which expressions might be useful for which purposes. For example, I usually suppose that "Kill this dog!" is, ceteris paribus, a good means of convincing someone else to kill this dog. In this sense, the applicability of, e.g., "dog" can be 'checked' regularly, for one can simply observe whether the application of "dog" is successful relative to one's prior assumptions.

${ }^{36}$ This is an immediate consequence of the definition of "ideal disposition".
} 
these extremes, i.e. significant changes take a number of generations to occur. $^{37}$ In a usage-based understanding, diachronic meaning shifts can be conceived of as a special case of relativisation (cf. first point). Meaning statements must be relativised to particular times (independently of disambiguation of indexical expressions). I contend that they normally are thus relativised (i.e. implicitly), and that this fact is obscured by choosing example sentences that involve only terms which are unlikely to undergo any significant meaning shifts within reasonable periods of time.

Consider "snow is white". Apparently, the 'constituents' of this sentence did not mean anything else three hundred years ago than they mean nowadays. Especially the ' $x$ is $y$ ' construction is relatively stable in regard to its semantics. Also, "white", denoting a colour, is unlikely to shift its meaning all too much within short periods of time (say, within a few generations). If anything, "snow" might undergo significant semantic shifts, for as we know from Inuit languages, it might be quite important to differentiate between sorts of snow, depending on how much one needs to interact with it. Overall, however, "snow". "white", and " $x$ is $y$ " have such a stable semantics that one easily gets the impression that it has always meant the same thing and always will mean the same thing, i.e. that snow is white.

A quite impressive meaning shift on historic scales concerns "weil" ("because'). Originally, "weil" simply functioned as a 'subordinating conjunction', i.e. as a conjunction that stands in initial position of a subordinate clause (Uhmann 1998). This is one extreme end of its semantic scale. At the other extreme, "weil" is used solely as a discourse marker, viz. as a means of negotiating metalevel aspects of conversations such as turn taking. Several shades of grey lie in between these extremes. From a philosophical perspective, two features of the meaning shift of "weil" are particularly interesting. Firstly, the shift happened-and still happens-astonishingly fast (a few speaker generations). Secondly, the semantically relevant aspects of "weil" in its discourse marker variety is hard to characterise as well as

${ }^{37}$ Cf. today's use of the German term "weil” as a discourse marker, parallel to its established use as subjunction and conjunction; which is a possibility that, in this form, did not exist fifty years ago (see below). In English, a parallel development can be observed with regard to "because" (or "cuz") that may also be used as a discourse marker in today's English (Schiffrin 1987). 
it is hard to locate particular "weil" instantiations on the continuum from subjunction to discourse marker. The first observation does not speak in favour or against any particular theory. It is only remarkable to the extent that common philosophy of language very often presupposes that natural language sentences express, plus-minus a bit, eternal contents (e.g. <snow is white>), which requires that, if meaning change occurs, there must be discrete steps in the shift from 'one' meaning to 'another'. However, in cases such as the meaning shift that affects "weil" such discrete steps are hardly identifiable.

The second observation is even more interesting in this regard. "Weil" as subjunction and conjunction is more or less easily identifiable:

While syntactic integration (finite verb at the end of the sentence) indicates a close link between two clauses and is primarily used to express factual causal relations ("des is besser, weil's schneller is"38), syntactic disintegration (verb following subject; V2) indicates a loose link between two clauses and contextualises a "weil" sentence as an independent assertion. Accordingly, "weil" in V2-position is typically associated with epistemic ("der hat sicher wieder gsoffen. weil sie läuft total deprimiert durch die Gegend"39) or speech-act-related causal relations ("warum kauft Ihr denn keine größeren Müslipäckchen. weil DIE reichen doch nirgends hin"40) (Gohl \& Günthner 1999, 40 , my translation, notation simplified)

As regards the use of "weil" as a discourse marker, though, its status within that class can only be specified rather vaguely. Moreover, the semantics of its discourse marker function is hard to specify. Most such uses seem to 'inherit'-at least partly-the original semantics, i.e. they indicate reasons. However, this only holds in a metaphorical sense: the explanations regarding "weil" may provide reasons for mentioning specific information (as opposed to giving reasons for why a particular state of affairs obtains). Other uses, again, lack even this 'core' semantics; they merely indicate that a

\footnotetext{
38 'This is better, because it is faster.'

39 'He must have been drinking again, because she looks so depressed.'

40 'Why don't you buy bigger packs of muesli? Because these will never be enough.'
} 
speaker wants to postpone turn taking. Thus, the semantics itself is hardly specifiable. Even worse, often different functions of "weil" within the discourse marker class seem to overlap. Gohl \& Günthner (1999) conclude that

The boundaries between [...] different discourse marker function associated with "weil" are sometimes uncertain. There are clear cases as well as a lot of overlaps, which is due to the fact that [...] "weil" can operate at different levels of discourse organisation. (54-55, my translation)

Abstracting from the particular difficulties of accounting for "weil", the philosophically interesting aspect here is that as soon as one turns to reallife examples, it is hard to ignore that many terms simply lack a clearly identifiable semantics. Rather, the semantics of many terms is-more or less-continuously evolving (on timescales of, say, decades). Describing the semantics of genuine natural language terms is necessarily an approximation. The development of "weil" shows, moreover, that referential relations-e.g. relating a main clause describing a state of affairs with another clause describing the reasons for why that state of affairs obtains-are particularly irrelevant in some cases. Rather, the meaning of a term like "weil" can be best described in terms of the conversational function that it fulfilsan element that is foreign to formal or truth-conditional semantics.

My primary intention is not to convince you of the ubiquity of semantic shifts. Rather, my point is that meaning shifts, prevalent as they are, have to be accommodated within a comprehensive theory of meaning. Usagebased approaches that cash out their main thesis in terms of dispositions are particularly likely to provide the easiest way of modelling meaning shifts. Simply put, the flexibility, mentioned above, to relativise dispositions to social groups is equally applicable to different times. Words mean and meant different things at different times due to the fact that people at different times had different overall dispositions to apply them.

\subsubsection{More On Dispositions}

I now want to describe in some more detail what I think a good dispositional analysis for word semantics might look like. To this end, I should say 
clearly that I think that Horwich's insights are brilliant and that the mechanisms he employs are excellent means for this specific purpose. The main worry that I have concerns the scope of his theory, i.e. my worry is that by saying that dispositional analyses in semantics must eventually recur to acceptance properties-i.e. the properties with which use properties get identified in Horwich's view-he is committed to a rather restricted theory of meaning that leaves the semantics of wide areas unspecified.

Dispositional analyses consist of two parts: they state certain antecedent conditions and they define what, given that the antecedent conditions hold, a manifestation of a disposition is. ${ }^{41}$ Horwich's analysis depicts particular such antecedent conditions and manifestations, namely 'the properties that explain [a term's] overall use and thereby provide it with the meaning it has' (Horwich 1998, 170). The problem here is that Horwich assigns a special role to declarative sentences in that the semantics of any given expression is identified with the role it plays in declaratives. Plausibly, the semantics of questions, for example, can be 'traced back' to acceptance properties. For example, the semantic contribution of "red" to "Is there a red elephant behind the door?" can plausibly be traced back to one's basic inclination to accept "This is red" when looking at something clearly red. But even if it is possible to employ this 'tracing back' strategy for some areas in linguistics, there are probably large areas in which this strategy fails. Examples include classes of words like "hello", "thing", "mongo", "gogogo", and so on. ${ }^{42}$ I come back to this in due course.

This is one reason for widening the scope of a Horwichian theory of meaning. Another one is this: reducing use properties to acceptance properties is-although it works in some areas-a strategy that is detached from what motivates language use in the first place. Therefore, a promising strategy to account for language use would be to ask first what language is used for, and then construe a dispositional analysis according to these insights. The idea is to scrutinise first which vocabulary gets employed in describing communication success (where the background assumption is that language use is primarily motivated by what leads to communicative

\footnotetext{
${ }^{41}$ Sugar is soluble (disposition): if sugar is put into water (antecedent condition), then it dissolves (manifestation).

${ }^{42}$ Probably, the strategy fails for a variety of different reasons in each case.
} 
successes). Arguably, this tells us, without further ado, which concepts are relevant for meaning statements. In a nutshell, the most important variables to which dispositional analyses arguably must be sensitive are situational circumstances, intentions, and language users. Let me now briefly justify my decision to take intentions into account.

As people have no direct access to the intentions of other people, do they therefore, in a broadly 'intention-based' theoretic framework, only know the meaning of their own words? No. Firstly, the intentions involved here do not concern meanings themselves (as in the Humpty Dumpty cases discussed by Davidson; see below for a discussion). The relevant intentions concern states (e.g. the state in which the salt gets passed). Intentions can't be observed directly, but they can be inferred from observable behaviour. That is to say, one may (i) reasonably hypothesise whether a given speaker's intention was to get some salt, and (ii) one may also observe whether an assumed aim was reached, i.e. whether some salt was passed (in which case the hypothesised intention was fulfilled). Incorporating intentions into one's semantic analysis is therefore not a constraint on people's possibilities to find out what others mean.

Secondly, the regular expectations that I, or others, have regarding the use of a word are governed by successful applications of the word in the past. These past successes are observable by anyone (given they successfully guessed my prior intentions before; otherwise it would be hard for them to distinguish successes from failures). The connection between observable behaviour and regularities in expectations is even stronger: the observability of successes pushes expectations into a particular direction (entrenchment). In other words: both from the hearer's as well as from the speaker's perspective, intentions are important in guiding future applications of linguistic expressions. Roughly put, to determine the likelihood of achieving one's aims by producing particular utterances, one needs to take into account the past success of similar utterances relative to the hypothesised intentions (hearer's perspective) or known intentions (speaker's perspective), respectively. ${ }^{43}$ I return to this further below.

${ }^{43}$ Although I do not want to pursue this any further at this point, it may be worth considering whether this little argument can be extended to a more general argument in favour of the relevance of intentions for semantics (as opposed to pragmatics). Horwich (1998) says about the normative power of the factual: '[...] the explanation [of the fact that 
Thirdly, expectations and intentions are, in effect, two sides of the same coin. Hence, 'Humpty Dumpty'-like cases can be excluded, because it is impossible to freely intend to mean something without taking into account what one would expect how a given utterance might be interpreted. Here is why. People want their intentions to be satisfied. ${ }^{44}$ Hence, deviant use, combined with the intention to be interpreted in a specific manner, only makes sense if this intention is made transparent. ${ }^{45}$ Otherwise, one would need to expect that one's utterances probably will be interpreted according to the usual practice, by which the alleged prior intentions were dissatisfied. $^{46}$

From an ontological perspective, intentions are peculiar. Especially so if they figure in theories of meaning. For instance, it might be questioned whether a specifically intention-based theory of meaning is naturalisable. An integral part of naturalism is the constraint that every theoretical statement must be open to scrutiny by everyone. Applied to my project, this

one ought to mean DOG by "dog"] is plainly pragmatic: it is good for [someone] to give words their English meanings because that is what member's of [one's] community do [...]' $(1998,186)$. I take it that a certain actual use per se can't enforce a particular future use. The reason is the following. My observation that people, including myself, in the past successfully 'referred' to dogs by uttering "dogs" is only interesting for me-i.e. a factor that could possibly guide my future use of "dog"- to the extent that I (implicitly) presuppose that this explains my past success in achieving dog-related aims and others' success in reaching theirs. In other words, the past success in using "dog" lies not in established reference (from "dog" to dogs) but in the achievement of dog-related aims (killing a dog by uttering "Kill that dog!"; conveying the information that this dog is brown by uttering "This dog is brown"; and so forth).

44 This is an analytic truth.

${ }^{45}$ The 'later' Davidson $(1986,258)$ is quite explicit about this:

[Humpty Dumpty, who intends to use "glory" with the meaning 'a nice knockdown argument,] cannot mean what he says he means because he knows that 'There's glory for you' cannot be interpreted by Alice as meaning 'There's a nice knockdown argument for you'. We know he knows this because Alice says 'I don't know what you mean by "glory" ', and Humpty Dumpty retorts, 'Of course you don't-til I tell you'.

${ }^{46}$ This is probably one major motivation that leads people to consider whether, e.g., text types could be treated as constructions. For text types (and the like) systematically determine certain, possibly 'deviant', interpretations. See note 5 for references. 
means: a meaning statement involving intentions is useless if, in principle, language users are unable to check others' intentions. But there is no reason to assume this in the first place. Consider an example already cited above; the intentions underlying utterances of "Could you pass the salt, please?" Here, the intentions themselves are not the direct objects of investigation. However, it is possible to observe everything else. And everything else surely is enough for having a reasonably broad basis of evidence, from which intentions can be derived. In fact, describing particular kinds of situations (for instance, those involving the above question) in terms of intentions just is a specific way of description. The only way to deny ascriptions of intentions in action explanations is via an intentioninvolving alternative description. ${ }^{47}$

To conclude, a theory of meaning should be open to involve explanations that recur to intentions and intention ascriptions, as this provides the opportunity to take into account the point of using language in the first place. The point of having language is, following Tomasello here, that it is a means that helps achieving common goals. ${ }^{48}$ Accordingly, appropriate dispositional analyses of individual terms are highly likely to recur to intentions and mindreading abilities. My point here is not that appropriate descriptions should generally involve intentions. Rather, this should be one possibility among many. For instance, I have repeatedly emphasised that the semantics of many terms can't be stated in terms of acceptance (and a fortiori not in terms of reference), but have to be described with regard to their conversational function. The meaning of an utterance like "How are

${ }^{47}$ Imagine that a person observes again and again that an utterance of "Could you pass the salt, please?" is followed by salt passing from the addressee to the speaker. These are observable behavioural patterns (utterances and reactions), hence uncritical from a naturalistic point of view. Observance of these regular patterns-and the correlation between the two actions-suffices in ascribing intentions to a given utterer of the question. (He probably intends to get salt.) From a naturalistic point of view, ascribing intentions is an observance-based strategy to explain kinds of behaviour. In slightly more philosophical prose, one does not necessarily need to be realist about intentions in order to employ them fruitfully in otherwise naturalistically uncritical explanations, i.e. explanations that recur to observables only.

${ }^{48}$ For constructionist frameworks of language acquisition, see Diessel (2007). For the relevance of cooperation, see Birch (2014) and Reich (2011). For mindreading in the Tomasellian paradigm, consult Moore, Liebal \& Tomasello (2013). 
you?" is to establish or cultivate a certain (temporal) social relationship. ${ }^{49}$ Correspondingly, a speaker understands "How are you?" if, in appropriate circumstances, she is typically disposed to utter that phrase in order to establish or maintain such a relationship. Hence, at least for certain classes of terms (phrases, etc.) it seems essential to allow that their corresponding meaning statements involve intention-based vocabulary.

${ }^{49}$ This is not to deny that "How are you?" also has a 'literal' reading, on which it can be interpreted as a request. The point is simply that a semantics that, due to omission of intentions, is restricted to describing this 'literal' meaning would fail to capture that aspect of meaning that is most relevant. 